
ultrafine particles

Department of Earth and Atmospheric Sciences, Cornell University, Ithaca, NY 14853.

(sp2279@cornell.edu)

Submitted as a Short Communication to Atmospheric Environment (10 June 2016).

Revised 21 July 2016

\title{
9 Highlights
}

10 1. Below-cloud scavenging coefficients derived from long-term particle measurements

112 . Scavenging coefficients decline by three as diameter goes from $15 \mathrm{~nm}$ to $100 \mathrm{~nm}$

12 3. Good agreement with empirical parameterization of Laakso et al. (2003) 


\section{Abstract}

14 Below-cloud scavenging coefficients for ultrafine particles (UFP) exhibit comparatively

15 large uncertainties in part because of the limited availability of observational data sets from

16 which robust parameterizations can be derived or that can be used to evaluate output from

17 numerical models. Long time series of measured near-surface UFP size distributions and

18 precipitation intensity from the Midwestern USA are used here to explore uncertainties in

19 scavenging coefficients and test both the generalizability of a previous empirical

20 parameterization developed using similar data from a boreal forest in Finland (Laakso et al.

21 2003) and whether a more parsimonious formulation can be developed. Scavenging coefficients

$22(\lambda)$ over an ensemble of 95 rain events (with a median intensity of $1.56 \mathrm{~mm} \mathrm{hr}^{-1}$ ) and 104 particle

23 diameter $\left(D_{p}\right)$ classes (from 10 to $400 \mathrm{~nm}$ ) indicate a mean value of $3.4 \times 10^{-5} \mathrm{~s}^{-1}$ (with a standard

24 error of $1.1 \times 10^{-6} \mathrm{~s}^{-1}$ ) and a median of $1.9 \times 10^{-5} \mathrm{~s}^{-1}$ (interquartile range: $-2.0 \times 10^{-5}$ to $7.5 \times 10^{-5} \mathrm{~s}^{-1}$ ).

25 The median scavenging coefficients for $\mathrm{D}_{\mathrm{p}}$ : 10-400 $\mathrm{nm}$ computed over all 95 rain events exhibit

26 close agreement with the empirical parameterization proposed by (Laakso et al. 2003). They

27 decline from $\sim 4.1 \times 10^{-5} \mathrm{~s}^{-1}$ for $\mathrm{D}_{\mathrm{p}}$ of $10-19 \mathrm{~nm}$, to $\sim 1.6 \times 10^{-5} \mathrm{~s}^{-1}$ for $\mathrm{D}_{\mathrm{p}}$ of $80-113 \mathrm{~nm}$, and show an 28 increasing tendency for $\mathrm{D}_{\mathrm{p}}>200 \mathrm{~nm}$.

30 Key words: below-cloud, particle removal, wet scavenging, observational, aerosol particles 


\section{Introduction and motivation}

Below-cloud scavenging of aerosol particles by hydrometeors plays an important role in

33 defining their atmospheric lifetimes and in situ particle size distributions (Andronache 2003;

34 Pruppacher and Klett 1997). Full numerical treatment of below-cloud scavenging in atmospheric

35 chemistry models is computationally demanding and is subject to large uncertainties due to non-

36 linear dependencies of scavenging efficiencies with hydrometeor diameter spectra and phase,

37 precipitation intensity, atmospheric turbulence and particle diameters (Andronache 2003;

38 Pruppacher and Klett 1997). Thus, some atmospheric chemistry models continue to use

39 scavenging coefficients expressed as a function of rainfall rate for specific particle diameters or

40 modes (Feng 2007) to represent this process (e.g. the EMEP MSC-W Eulerian chemical

41 transport model (Simpson et al. 2012), DEHM (Frohn et al. 2001), and MATCH (Robertson et

42 al. 1999)).

43 A number of previous publications have explained the mechanisms and theorized

44 dependencies of below-cloud scavenging (e.g. (Andronache 2003; Pruppacher and Klett 1997;

45 Wang et al. 2010)), so they are described only briefly here. The rate at which particles are

46 scavenged by rain droplets depends on the collision and collection efficiency (where the latter

47 term is often assumed to be 1 for particles with diameters much smaller than the rain droplet

48 diameter), and is thus a function of the rainfall intensity and rain droplet size distribution, as well

49 as the size distribution and composition of the in situ particles. The collision efficiency $\left(E\left(D, D_{p}\right)\right)$

50 between a falling raindrop of a given diameter (D) and an in situ particle (of diameter, $\mathrm{D}_{\mathrm{p}}$ ) is

51 theorized to decrease with increasing particle diameter in the $\mathrm{D}_{\mathrm{p}}$ range $\sim 1-100 \mathrm{~nm}$, to remain

52 fairly constant (i.e. within a factor of approximately 2-5) in the $\mathrm{D}_{\mathrm{p}}$ range $\sim 100 \mathrm{~nm}$ to $1 \mu \mathrm{m}$, and

53 then to exhibit a rapid increase with increasing $D_{p}$ (Wang et al. 2010). $E\left(D, D_{p}\right)$ for the smallest 
$54 \quad \mathrm{D}_{\mathrm{p}}$ is dominated by Brownian diffusion with additional contributions from thermophoresis and

55 electrostatic forces (Andronache 2004), and atmospheric turbulence (Quérel et al. 2014). For

56 larger $\mathrm{D}_{\mathrm{p}}$ interception and impaction play a larger role in dictating collision efficiency

57 (Pruppacher and Klett 1997; Wang et al. 2010). $\mathrm{E}\left(\mathrm{D}, \mathrm{D}_{\mathrm{p}}\right)$ increases with $\mathrm{D}$, so given rainfall

58 events with lower intensities (rainfall rates) are typically characterized by smaller rain droplet

59 diameters than those with higher intensities (Marshall and Palmer 1948), the a priori expectation

60 is that higher rainfall rates are typically associated with a larger number of larger rain droplets,

61 and thus higher particle scavenging efficiencies. This expectation has largely been realized in

62 observational analyses (e.g. (Castro et al. 2010; Chate 2005; Laakso et al. 2003; Maria and

63 Russell 2005; Volken and Schumann 1993; Zhao et al. 2015). However, there are large event-to-

64 event and site-to-site variations in experimentally derived scavenging efficiencies (Andronache

65 et al. 2006). Of the observational studies of below-cloud scavenging of ultrafine particles (UFP,

66 particles with diameters $\left(D_{p}\right)$ less than $100 \mathrm{~nm}$ ) that have been conducted to date, only two

67 (Laakso et al. 2003; Zikova and Zdimal 2016) have considered sufficient rain event sample sizes

$68(\mathrm{n} \approx 100)$ to generate statistically robust estimates of size-resolved scavenging coefficients, and

69 only one (Laakso et al. 2003) sought to develop an empirical parameterization of size-resolved

70 scavenging coefficients. Herein, we use a 30-month time series of measured near-surface UFP

71 size distributions and precipitation intensity to explore the generalizability of the empirical

72 parameterization of (Laakso et al. 2003), and to evaluate whether alternative, more parsimonious

73 formulations can be advanced.

\section{Data and methods}

The meteorological and particle size distribution (PSD) data analyzed herein were

76 collected at an AmeriFlux site in southern Indiana (in the Morgan Monroe State Forest (MMSF), 
$39^{\circ} 19^{\prime} \mathrm{N}, 86^{\circ} 25^{\prime} \mathrm{W}, 275 \mathrm{~m}$ a.s.l., (Schmid et al. 2000)) from December 2006 to April 2009.

78 Precipitation at this site is fairly evenly distributed across the year and has an average occurrence

79 of approximately 1 day in 3 (see précis description of the meteorological conditions in Figure 1).

80 Size-resolved particle number concentrations in 104 size classes over the $D_{p}$ range: $10-400 \mathrm{~nm}$

81 were obtained using a TSI scanning mobility particle sizer (SMPS3936) system comprising an

82 electrostatic classifier (TSI-3080), long differential mobility analyzer (TSI-DMA3081) and a

83 condensation particle counter (TSI-3025A). A second SMPS3936 system was also operated on

84 the same manifold and comprised an electrostatic classifier (TSI-3080), nano-DMA (TSI-

85 DMA3085) and a condensation particle counter (TSI-3786) and for which particle concentrations

86 for $\mathrm{D}_{\mathrm{p}}$ in the range 6-100 $\mathrm{nm}$ are reported. The sampling protocol was such that air was drawn

87 from a height of 46-m (above a forest canopy with a mean height $\sim 26-28 \mathrm{~m}$ ) through copper

88 tubing for 10-minutes in each half-hour period, with sampling at two other heights via a common

89 manifold in each 30-minute period (Pryor et al. 2010). Copper was chosen for the sampling lines

90 because it was available at very long sections reducing the number of connections to two, is

91 malleable (meaning all bends could be relatively smooth) and is relatively inert and resistant to

92 acquisition of charge, but with such long sampling lines particle losses are inevitable. Thus,

93 transmission efficiencies derived experimentally (which for $\mathrm{D}_{\mathrm{p}}=10 \mathrm{~nm}$ are below 0.3 , but

94 increase to over 0.5 for $\mathrm{D}_{\mathrm{p}}>20 \mathrm{~nm}$ ) were used to determine empirical correction factors (Pryor

95 et al. 2010) that have been applied to the observed PSD. We assume the particle losses in the

96 copper sampling lines are independent of variations in humidity and other environmental

97 conditions.

98 Rainfall rates derive from measurements using a Texas Electronics TE525 tipping bucket

99 rain gauge also deployed at $46 \mathrm{~m}$ (Figure 1b). Since this instrument is deployed without a wind- 
shield it is subject to under-capture during high wind events. The modal correction factor computed using the approach of (Hildebrandt et al. 2007) and wind speed data from a sonic

102 anemometer deployed at 46-m is $\sim 1.1$ (Figure $2 \mathrm{~b}$ ). Frozen hydrometeors (snow, ice and hail)

103 differ greatly from liquid droplets both in terms of the particle capture efficiencies (Sparmacher

104 et al. 1993) and the accuracy of their measurement by tipping bucket rain gauges (Savina et al.

105 2012). To avoid inclusion of snow events in the analysis, METAR reports from the National

106 Weather Service station KIND-Indianapolis, IN (located approximately $45 \mathrm{~km}$ to the north of

107 MMSF) are used to screen out periods when snow or hail was observed. The procedure used is as

108 follows; any event during which precipitation is reported by the TE525 at MMSF and for which

109 snow/ice/hail were reported at KIND during that hour or the two hours prior to or subsequent to

110 that time stamp are excluded from consideration. The resolution of the tipping bucket rain gauge

111 is $0.254 \mathrm{~mm}$ (equal to one tip). To be consistent with the analysis of (Laakso et al. 2003) and

112 avoid inclusion of very light and comparatively poorly quantified rain events, events were only

113 included in the analysis if the precipitation intensity $\geq 0.4 \mathrm{~mm} \mathrm{hr}^{-1}$.

114 The in situ measured PSDs and rainfall rates are used to derive size-resolved scavenging

115 coefficients $\left(\lambda\left(D_{p}\right)\right)$ using:

116

$$
\lambda\left(D_{p}\right)=-\frac{1}{t_{1}-t_{0}} \ln \left(\frac{c_{1}\left(D_{p}\right)}{c_{0}\left(D_{p}\right)}\right)
$$

117 Where $D_{p}$ is the particle diameter, $t_{1}-t_{0}$ is the length of the rain event in seconds, and $c_{0}\left(D_{p}\right)$ and

$118 \mathrm{c}_{1}\left(\mathrm{D}_{\mathrm{p}}\right)$ are the average number concentration of particles in each size bin in the 30 -minute

119 periods before and after the rain event, respectively.

A premise of the empirical approach to determining size-resolved scavenging efficiencies

121 is that with the exception of removal by below-cloud scavenging the particle population is

122 stationary over the course of the rain event. To avoid strongly non-stationary conditions such as 
123 frontal passages or new particle formation occurrence, events are only included in the analysis if

124 two criteria are met: (i) the wind direction (as measured using a 03001-5 R.M. Young Wind

125 Sentry Set deployed at 46-m) at the start and end of the rain event did not differ by more than $90^{\circ}$

126 and (ii) new particle formation (NPF) was not observed in the hour following cessation of rain

127 (i.e. particle concentrations $<1 \times 10^{3} \mathrm{~cm}^{-3}$ for $\mathrm{D}_{\mathrm{p}}=10-15 \mathrm{~nm}$, inclusive and visual inspection of

128 plots of the time evolution of PSD did not show evidence of NPF (see a detailed description of

129 robust subjective and objective ways to detect NPF given in (Kulmala et al. 2012))). To avoid

130 unstable estimates of the concentration ratio, an individual diameter class was only included in

131 the analysis of a specific rain event if both $\mathrm{c}_{0}\left(\mathrm{D}_{\mathrm{p}}\right)$ and $\mathrm{c}_{1}\left(\mathrm{D}_{\mathrm{p}}\right)$ exceeded $10 \mathrm{~cm}^{-3}$.

132 (Laakso et al. 2003) proposed the following functional form for the relationship between

133 the median $\lambda\left(D_{p}\right)$ (for each of the 29 logarithmically distributed size channels $\left(D_{p}\right)$ in the

134 diameter space $10-500 \mathrm{~nm}$ ) and precipitation rate:

135

$$
\log _{10}\left(\frac{\lambda}{\lambda_{0}}\right)=a+b \times d_{p}^{-4}+c \times d_{p}^{-3}+d \times d_{p}^{-2}+e \times d_{p}^{-1}+f \times
$$

$136\left(\frac{p}{p_{0}}\right)^{0.5}$

137 Where $\lambda_{0}$ is $1 \mathrm{~s}^{-1}, \mathrm{~d}_{\mathrm{p}}=\log _{10}\left(\mathrm{D}_{\mathrm{p}} / \mathrm{D}_{\mathrm{p} 0}\right), \mathrm{D}_{\mathrm{p} 0}=1 \mathrm{~m}, \mathrm{p}$ is the rain rate in $\mathrm{mm} \mathrm{hr}^{-1}, \mathrm{p}_{0}$ is $1 \mathrm{~mm} \mathrm{hr}^{-1}$, and $138 a-f$ are the fitted coefficients.

In this analysis, we evaluate the degree of agreement between the empirical coefficients

140 (a-f) as derived by (Laakso et al. 2003) and observational estimates of $\lambda\left(D_{p}\right)$ as derived from the

141 MMSF data set. We also use the framework described by (2) to develop least squares best-fit

142 estimates from our observations. Our fitting procedure is as follows: the coefficient $f$ (which

143 describes the scaling term for precipitation intensity) is first derived by conditionally sampling

144 the scavenging coefficients in three precipitation intensity classes (light $\left(0.4-2 \mathrm{~mm} \mathrm{hr}^{-1}\right)$,

145 moderate $\left(2-5 \mathrm{~mm} \mathrm{hr}^{-1}\right)$, and heavy $\left.\left(>5 \mathrm{~mm} \mathrm{hr}^{-1}\right)\right)$ in addition to treating the whole sample 
ensemble (i.e. all rainfall intensities). Then $f$ and the median value of $p$ is used with the estimates

147 of $\log _{10}\left(\frac{\lambda}{\lambda_{0}}\right)$ as a composite dependent variable to generate the other fitting coefficients in

148 equation (2). Application of regression to fit complex (multi-predictor) equations (such as (2)) to

149 small data sets can lead to model over-fitting. Hence we use stepwise regression to examine if a

150 more parsimonious fit can be derived. In this analysis we use stepwise regression with a

151 threshold minimum $\mathrm{p}$-value of 0.1 for a term to be removed.

152 There are four primary potential sources of discrepancies between empirically derived

$153 \lambda\left(D_{p}\right)$ from different studies:

154 a) Variations in the methodology used to select the cases (e.g. the stationarity criteria) 155 and those used to compute the scavenging coefficients (e.g. the discretization of the 156 precipitation data). The precipitation data at the MMSF site are reported with hourly 157 discretization, while (Laakso et al. 2003) had precipitation rates discretized at 15minute intervals and they included all events with a duration $>0.5$ hours. The hourly discretization of precipitation data from MMSF will inevitably result in lower 160 precipitation intensities than if the precipitation data were discretized at higher frequency. Also, herein we compare UFP concentrations before and after rain events to capture the net effect of the precipitation event. That is we compare distributions at $\mathrm{t}=0$, prior to the commencement of precipitation, and at time $\mathrm{t}=\mathrm{n}$, after precipitation and thus each individual event results in a single estimate of $\lambda$ for each particle diameter so each event is equally weighted in the estimation of median and mean $\lambda\left(D_{p}\right)$ regardless of the event duration. However, previous authors calculated $\lambda$ from the UFP concentrations during rain events and thus compare the PSD at time $\mathrm{t}=0$, just prior to precipitation and at time $=\mathrm{t}+\mathrm{n}$, and at $\mathrm{t}+\mathrm{n}$ and $\mathrm{t}+2 \mathrm{n}$, (where $\mathrm{n}$ is the temporal 
discretization of the PSD measurements) during the rain event (Laakso et al. 2003; Zikova and Zdimal 2016).

171 b) Variations in the sampling system. Here we present data that were sampled well above a forest canopy to avoid local contamination of the PSD, and thus used long sampling lines that result in large corrections for tubing losses. Other sampling locations may not require use of long sampling lines.

175 c) Differences in particle instrumentation both in terms of operating principle (e.g. SMPS versus Fast Mobility Particle Sizers (Hornsby and Pryor 2014)) and the discretization of the PSD. Also differences in instrument maintenance and deployment protocols (e.g. the presence of a wind shielding on, or heating of, rain gauges).

d) Differences in the type and intensity of precipitation and thus the rain droplet size distribution.

To address some of these sources of uncertainty we compute $\lambda\left(D_{p}\right)$ from two different

182 SMPS3936 systems connected to the same sampling lines and manifold system. One SMPS was 183 operated with a long-DMA in order to capture a wide range of particles diameters $(10-400 \mathrm{~nm})$,

184 and one with a short-DMA to provide estimates of scavenging coefficients for $\mathrm{D}_{\mathrm{p}}<100 \mathrm{~nm}$ for a 185 larger event sample (i.e. more rain events), and also undertake an assessment of $\lambda\left(D_{p}\right)$ for the 186 diameter range 10-100 $\mathrm{nm}$ for rainfall events sampled by both SMPS systems.

\section{Results}

The rain events used to compute the scavenging coefficients from the SMPS3936 with a

189 long-DMA exhibit a mean duration of almost 3 hours (median of 2 hours) and a mean intensity 190 of $2.47 \mathrm{~mm} \mathrm{hr}^{-1}$ (median of $1.57 \mathrm{~mm} \mathrm{hr}^{-1}$ ) (Figure 2 and Table 1). Thus, the average rain 
191 intensities are higher than those reported in (Laakso et al. 2003) (median value of $0.8 \mathrm{~mm} \mathrm{hr}^{-1}$ ), 192 but cover the same range of values.

Although a substantial fraction of the scavenging coefficients $(\lambda)$ from (1) are close to (or

194 below) zero, the mean- $\lambda$ is significantly different from zero and positive. We postulate that the

195 negative $\lambda$ values (that have also been observed in previous studies (Laakso et al. 2003; Zikova

196 and Zdimal 2016)) reflect causes such as the uncertainty in PSD measurements and inclusion

197 cases where the PSD was non-stationary events (although the event passed our selection criteria).

198 The empirical cumulative density function of $\lambda$ over the ensemble of rain events and 104

199 diameter classes indicate a mean value of $3.4 \times 10^{-5} \mathrm{~s}^{-1}$ (with a standard error of $1.1 \times 10^{-6} \mathrm{~s}^{-1}$ ), a

200 median of $1.9 \times 10^{-5} \mathrm{~s}^{-1}$, and an interquartile range of $-2.0 \times 10^{-5}$ to $7.5 \times 10^{-5} \mathrm{~s}^{-1}$ (Figure 3a, Table 1).

201 To provide further context for these estimates of $\lambda$ an analysis was conducted in which number

202 concentrations from the 104 size classes were sampled across 95 randomly sampled "no rain"

203 events (that have the same characteristics in terms of duration and stationarity conditions applied

204 above) and used to compute scavenging coefficients. The results indicate a mean value

205 (computed over all diameters and all events) of $4.8 \times 10^{-6} \mathrm{~s}^{-1}$ (with a standard error of $2.8 \times 10^{-6} \mathrm{~s}^{-}$

$20{ }^{1}$ ), and a median of $-1.0 \times 10^{-7} \mathrm{~s}^{-1}$ (interquartile range: $-7.7 \times 10^{-6}$ to $1.0 \times 10^{-5} \mathrm{~s}^{-1}$ ). Thus, the mean- $\lambda$

207 for non-rain events is almost an order of magnitude below that obtained for our rain event

208 ensemble, and the median is over an order of magnitude smaller than that computed for the rain

209 events. This analysis thus further indicates that, while there is considerable event-to-event

210 variability in derived $\lambda$ estimates, the estimates derived herein are likely reflective of physical

211 removal of particles by below-cloud scavenging. Further, although as in the study of (Zikova and

212 Zdimal 2016) the interquartile range of $\lambda\left(D_{p}\right)$ spans an order of magnitude for virtually all

213 diameters considered (Figure $3 b$ ), only two measured $D_{p}$ exhibit mean- $\lambda$ values that are negative 
214 and they are confined to diameters $(10.9 \mathrm{~nm}$ and $399.5 \mathrm{~nm})$ near the edges of the measured

215 interval for this SMPS where the instrument has lower precision, and for the smaller diameter

216 where the correction for tubing losses is largest.

217 The magnitude of median- $\lambda\left(D_{p}\right)$ agree with previously reported theoretical predictions

218 (Wang et al. 2010) for the range of rainfall intensities represented in the data set. Also in accord

219 with theoretical considerations and prior experimental research (Andronache et al. 2006; Wang

220 et al. 2010), median scavenging coefficients by particle diameter computed over all 95 rain

221 events decline from $\sim 4.1 \times 10^{-5} \mathrm{~s}^{-1}$ for $\mathrm{D}_{\mathrm{p}}$ of $10-19 \mathrm{~nm}$ to $\sim 1.6 \times 10^{-5} \mathrm{~s}^{-1}$ for $\mathrm{D}_{\mathrm{p}}$ of $80-113 \mathrm{~nm}$, and

222 then show an increasing tendency for $D_{p}>200 \mathrm{~nm}$ (Figure 3b).

223 Scavenging coefficients for all $\mathrm{D}_{\mathrm{p}}$ were conditionally sampled by rainfall intensity

224 (Figure 3a) to derive an estimate of the coefficient $f$ in (2) as the slope of the fit between median-

$225 \lambda$ and rainfall intensity. The results indicate a value of 0.185 (versus 0.244984 in (Laakso et al.

226 2003)). The other coefficients in (2) were then determined by first averaging the median $\lambda$

227 estimates across three size channels (so median $\lambda\left(D_{p}\right)$ is the average value of $\lambda\left(D_{p}(n-1), \lambda\left(D_{p}(n)\right.\right.$,

228 and $\lambda\left(D_{\mathrm{p}}(\mathrm{n}+1)\right)$ and then fitting (2) using least squares regression (Figure 4). The resulting fit has

229 an adjusted variance explanation (adjusted- $\mathrm{r}^{2}$ ) of 0.46 , and all values of the coefficients have $\mathrm{p}$ -

230 values $<0.10$. No more parsimonious model could be found using stepwise regression. Thus it

231 appears that all the terms in equation (2) contribute to the overall quality of the fit.

232 Although the fitting coefficients from MMSF exhibit marked discrepancies from those

233 developed by (Laakso et al. 2003), the median $\lambda\left(D_{p}\right)$ values computed from the MMSF data set

234 also exhibit good agreement with the parameterization of (Laakso et al. 2003) (Figure 4). The

235 root mean squared error (RMSE) between $\lambda$ from the fit derived herein and the observations for

236 the 104 diameter classes is $1.23 \times 10^{-5} \mathrm{~s}^{-1}$ (for the median precipitation intensity of $1.56 \mathrm{~mm} \mathrm{hr}^{-1}$ ), 
237 while for the (Laakso et al. 2003) parameterization is only slightly higher $\left(1.63 \times 10^{-5} \mathrm{~s}^{-1}\right)$. Thus,

238 the parameterization of median $\lambda\left(D_{\mathrm{p}}\right)$ derived by (Laakso et al. 2003) appears to be broadly

239 applicable. Interestingly, in contrast to the convergence with estimates from the boreal forest site

240 in Finland (reported by (Laakso et al. 2003)), for all diameters data from MMSF indicate

241 substantially smaller $\lambda\left(D_{\mathrm{p}}\right)$ than were derived using data from a site in the Czech Republic

242 (Zikova and Zdimal 2016) (Figure 4). This discrepancy may reflect the occurrence of higher

243 rainfall intensities at the site in the Czech Republic, differences due to the criteria used for event

244 selection with regards to stationarity, and/or difference in the way in which scavenging

245 coefficients are calculated (described above).

246 Median- $\lambda\left(D_{\mathrm{p}}\right)$ computed from the SMPS3936 with the nano-DMA for a larger set of

247 rainfall events at MMSF $(n=121$, see Table 1$)$ generally exceed those from the SMPS with a

248 long-DMA (Figure 4). The $\lambda$ estimates from the nano-DMA SMPS data set at MMSF are also

249 smaller than those from the site in the Czech Republic, but by a lower margin than those from

250 the SMPS with a long-DMA (Figure 4). This may be in part due to the inclusion of more

251 summertime rainfall events in the sample used to compute $\lambda\left(D_{p}\right)$ from the SMPS with the nano-

252 DMA (see Figure 1c). To provide a context for these results computed independently from the

253 two SMPS systems at MMSF (over different rain events), $\lambda$ estimates for $D_{p} 10-100 \mathrm{~nm}$ from the

254 two systems for 87 common rainfall events were also computed. The results indicate relatively

255 good agreement between $\lambda\left(D_{\mathrm{p}}\right)$ estimates from the two systems (Table 1, Figure 5) adding

256 support to the inference that the discrepancies shown in Figure 4 reflect differences in the nature

257 of the rainfall events. 


\section{Concluding remarks}

259 Below cloud scavenging is an important removal process for atmospheric aerosol

260 particles and plays a key role in determining particle concentrations and size distributions. The

261 magnitude of the effect remains uncertain in part because there remain very few robust

262 observational data sets with which to evaluate numerical models of scavenging efficiencies. In

263 situ measurements of particle size distributions and rainfall intensities collected over a 30-month

264 period are used to develop a data set of rain events from which scavenging efficiencies for

265 particle diameters between 10 and $400 \mathrm{~nm}$ are derived. The ensemble mean scavenging

266 efficiency is $3.4 \times 10^{-5} \mathrm{~s}^{-1}$ (and has a standard error of $1.1 \times 10^{-6} \mathrm{~s}^{-1}$ ), while the median is $1.9 \times 10^{-5} \mathrm{~s}^{-}$

$267{ }^{1}$ (interquartile range: $-2.0 \times 10^{-5}$ to $7.5 \times 10^{-5} \mathrm{~s}^{-1}$ ). The median scavenging coefficients by particle

268 diameter exhibit good agreement with the empirical expression formulated by (Laakso et al.

269 2003).

\section{Acknowledgments}

This work was support by a grant to SCP from NSF (1517365). RCS acknowledges

272 funding from NASA (14-EARTH14F-0207). The comments and suggestions of two reviewers

273 and Prof. R. Barthelmie are gratefully acknowledged. The PSD data from MMSF analyzed

274 herein can be downloaded from http://www.geo.cornell.edu/eas/PeoplePlaces/Faculty/spryor/ or

275 can be requested by email (sp2279@cornell.edu). The AmeriFlux data used herein (available at:

276 http://ameriflux.ornl.gov/) were collected under funding from the Office of Science, US

277 Department of Energy, and from the AmeriFlux Management Project, Lawrence Berkeley

278 National Laboratory. Observations of meteorological conditions from the NWS station in

279 Indianapolis are available from the National Centers for Environmental Information

280 (ftp://ftp.ncdc.noaa.gov/pub/data/). 
282 Andronache, C., 2003: Estimated variability of below-cloud aerosol removal by rainfall for

283 observed aerosol size distributions. Atmos. Chem. Phys., 3, 131-143.

284 Andronache, C., 2004: Diffusion and electric charge contributions to below-cloud wet removal 285 of atmospheric ultra-fine aerosol particles. Journal of Aerosol Science, 35, 1467-1482.

286 Andronache, C., T. Grönholm, L. Laakso, V. Phillips, and A. Venäläinen, 2006: Scavenging of 287 ultrafine particles by rainfall at a boreal site: observations and model estimations. Atmos. Chem. 288 Phys., 6, 4739-4754.

289 Castro, A., E. Alonso-Blanco, M. González-Colino, A. I. Calvo, M. Fernández-Raga, and R. 290 Fraile, 2010: Aerosol size distribution in precipitation events in León, Spain. Atmospheric

291 Research, 96, 421-435.

292 Chate, D. M., 2005: Study of scavenging of submicron-sized aerosol particles by thunderstorm 293 rain events. Atmospheric Environment, 39, 6608-6619.

294 Feng, J., 2007: A 3-mode parameterization of below-cloud scavenging of aerosols for use in 295 atmospheric dispersion models. Atmospheric Environment, 41, 6808-6822.

296 Frohn, L. M., J. H. Christensen, J. Brandt, and O. Hertel, 2001: Development of a high resolution 297 integrated nested model for studying air pollution in Denmark. Physics and Chemistry of the 298 Earth, Part B: Hydrology, Oceans and Atmosphere, 26, 769-774.

299 Hildebrandt, A., M. Al Aufi, M. Amerjeed, M. Shammas, and E. A. B. Eltahir, 2007:

300 Ecohydrology of a seasonal cloud forest in Dhofar: 1. Field experiment. Water Resources 301 Research, 43, n/a-n/a. 
302 Hornsby, K. E., and S. C. Pryor, 2014: A Laboratory Comparison of Real-Time Measurement

303 Methods for 10-100-nm Particle Size Distributions. Aerosol Science and Technology, 48, 571-

304582.

305 Kulmala, M., and Coauthors, 2012: Measurement of the nucleation of atmospheric aerosol

306 particles. Nature Protocols, 7, 1651-1667.

307 Laakso, L., T. Gronholm, Ü. Rannik, M. Kosmale, V. Fieldler, H. Vehkamaki, and M. Kulmala, 308 2003: Ultrafine particle scavenging coefficients calculated from 6 years field measurements.

309 Atmospheric Environment, 37, 3605-3613.

310 Maria, S. F., and L. M. Russell, 2005: Organic and inorganic aerosol below-cloud scavenging by

311 suburban New Jersey precipitation. Environmental science \& technology, 39, 4793-4800.

312 Marshall, J. S., and W. M. K. Palmer, 1948: The distribution of raindrops with size. Journal of

313 meteorology, 5, 165-166.

314 Pruppacher, H. R., and J. D. Klett, 1997: Chapter 17: Cloud chemistry. Microphysics of clouds

315 and precipitation, Kluwer Academic Publishers, Dordrecht, 700-791.

316 Pryor, S., A. Spaulding, and R. Barthelmie, 2010: New particle formation in the Midwestern

317 USA: Event characteristics, meteorological context and vertical profiles. Atmospheric

318 Environment, 44, 4413-4425.

319 Quérel, A., M. Monier, A. I. Flossmann, P. Lemaitre, and E. Porcheron, 2014: The importance of 320 new collection efficiency values including the effect of rear capture for the below-cloud

321 scavenging of aerosol particles. Atmospheric Research, 142, 57-66.

322 Robertson, L., J. Langner, and M. Engardt, 1999: An Eulerian limited-area atmospheric transport 323 model. Journal of Applied Meteorology, 38, 190-210. 
324 Savina, M., B. Schäppi, P. Molnar, P. Burlando, and B. Sevruk, 2012: Comparison of a tipping325 bucket and electronic weighing precipitation gage for snowfall. Atmospheric Research, 103, 4532651.

327 Schmid, H. P., C. S. B. Grimmond, F. Cropley, B. Offerle, and H.-B. Su, 2000: Measurements of $328 \mathrm{CO} 2$ and energy fluxes over a mixed hardwood forest in the midwestern United States.

329 Agricultural and Forest Meteorology, 103, 357-374.

330 Simpson, D., and Coauthors, 2012: The EMEP MSC-W chemical transport model - technical 331 description. Atmospheric Chemistry and Physics, 12, 7825-7865.

332 Sparmacher, H., K. Fülber, and H. Bonka, 1993: Below-cloud scavenging of aerosol particles:

333 Particle-bound radionuclides—Experimental. Atmospheric Environment, 27, 605-618.

334 Volken, M., and T. Schumann, 1993: A Critical review of below-cloud aerosol scavenging 335 results on Mt. Rigi. Water, Air, and Soil Pollution, 68, 15-28.

336 Wang, X., L. Zhang, and M. D. Moran, 2010: Uncertainty assessment of current size-resolved 337 parameterizations for below-cloud particle scavenging by rain. Atmos. Chem. Phys., 10, 56853385705.

339 Zhao, S., Y. Yu, J. He, D. Yin, and B. Wang, 2015: Below-cloud scavenging of aerosol particles 340 by precipitation in a typical valley city, northwestern China. Atmospheric Environment, 102, 7034178.

342 Zikova, N., and V. Zdimal, 2016: Precipitation scavenging of aerosol particles at a rural site in 343 the Czech Republic. Tellus B, 68, 27343, doi: 27310.23402/tellusb.v27368.27343. 
346 Table 1. Summary of the data sets from which scavenging coefficients were computed for MMSF and the resulting statistics.

\begin{tabular}{|c|c|c|c|c|}
\hline Statistic $\Downarrow /$ Instrument $\Rightarrow$ & $\begin{array}{l}\text { SMPS3936: } \\
\text { Long-DMA }\end{array}$ & $\begin{array}{l}\text { SMPS3936: } \\
\text { Nano-DMA }\end{array}$ & $\begin{array}{c}\text { Common } \\
\text { events } \\
\text { Long- } \\
\text { DMA }\end{array}$ & $\begin{array}{c}\text { Common } \\
\text { events } \\
\text { Nano- } \\
\text { DMA }\end{array}$ \\
\hline$D_{p}$ range $(\mathrm{nm})$ & $10-400$ & $6-100$ & \multicolumn{2}{|c|}{$10-100$} \\
\hline \# rainfall events & 95 & 121 & \multicolumn{2}{|c|}{87} \\
\hline $\begin{array}{l}\text { Mean rainfall intensity } \\
\left(\mathrm{mm} \mathrm{hr}^{-1}\right) \text { (median) }\end{array}$ & $2.47(1.56)$ & $2.46(1.59)$ & \multicolumn{2}{|c|}{$2.55(1.48)$} \\
\hline $\begin{array}{l}\text { Mean- } \lambda\left(10^{-5} \mathrm{~s}^{-1}\right) \\
\text { (standard error) }\end{array}$ & $3.4(0.11)$ & $3.5(0.32)$ & $4.6(0.25)$ & $3.2(0.28)$ \\
\hline Median $-\lambda\left(10^{-5} \mathrm{~s}^{-1}\right)(\mathrm{IQR})$ & $1.9(-2.0$ to 7.5$)$ & $5.7(-1.7$ to 11$)$ & $\begin{array}{c}2.6(-1.5 \text { to } \\
8.8)\end{array}$ & $\begin{array}{c}2.2(-2.3 \text { to } \\
8.1)\end{array}$ \\
\hline $\begin{array}{l}\text { RMSE of median- } \lambda\left(D_{p}\right) \\
\text { versus fit }\left(10^{-5} \mathrm{~s}^{-1}\right)\end{array}$ & 1.23 & 1.26 & & \\
\hline $\begin{array}{l}\text { RMSE of median- } \lambda\left(D_{\mathrm{p}}\right) \\
\text { versus fit of Laakso et al. } \\
\left(10^{-5} \mathrm{~s}^{-1}\right)\end{array}$ & 1.63 & 3.95 & & \\
\hline
\end{tabular}



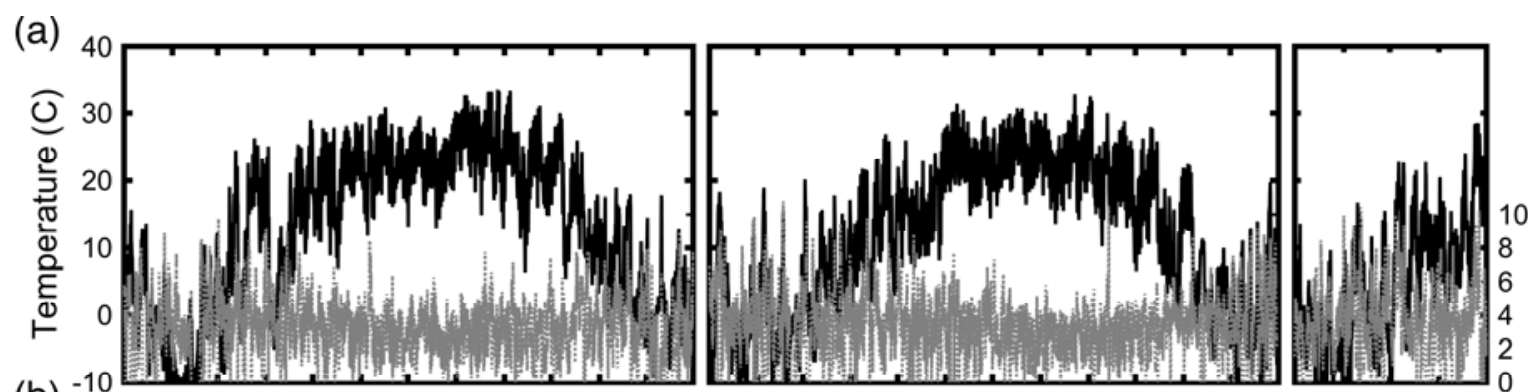

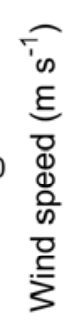
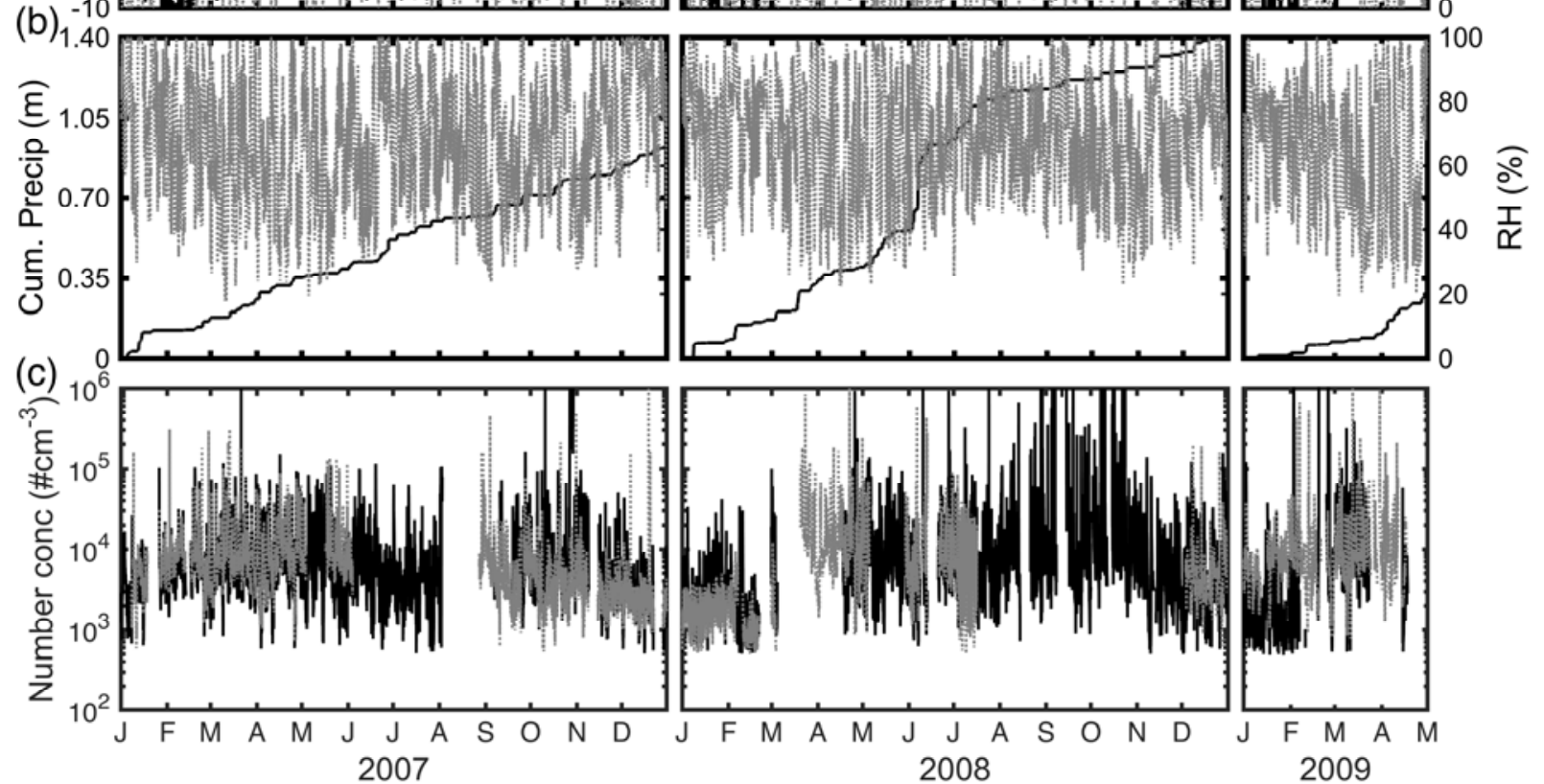

Figure 1. Overview of meteorological conditions and particle number concentrations at MMSF

352 during January 2007-April 2009. (a) Hourly average air temperature $\left({ }^{\circ} \mathrm{C}\right)$ (black) and wind

353 speed $\left(\mathrm{ms}^{-1}\right)$ (gray) at 46-m. (b) Cumulative precipitation (Cum. Precip, $m$ ) in each year (black)

354 and hourly average relative humidity ( $R H, \%$ ) again at 46-m. (c) Total number particle

355 concentrations (\# $\left.\mathrm{cm}^{-3}\right)$ at 46-m (Number conc) from an SMPS with a nano-DMA ( $\left.D_{p}: 6-100 \mathrm{~nm}\right)$

(black) and an SMPS with a long-DMA ( $\left.D_{p}: 10-400 \mathrm{~nm}\right)$ (gray). 


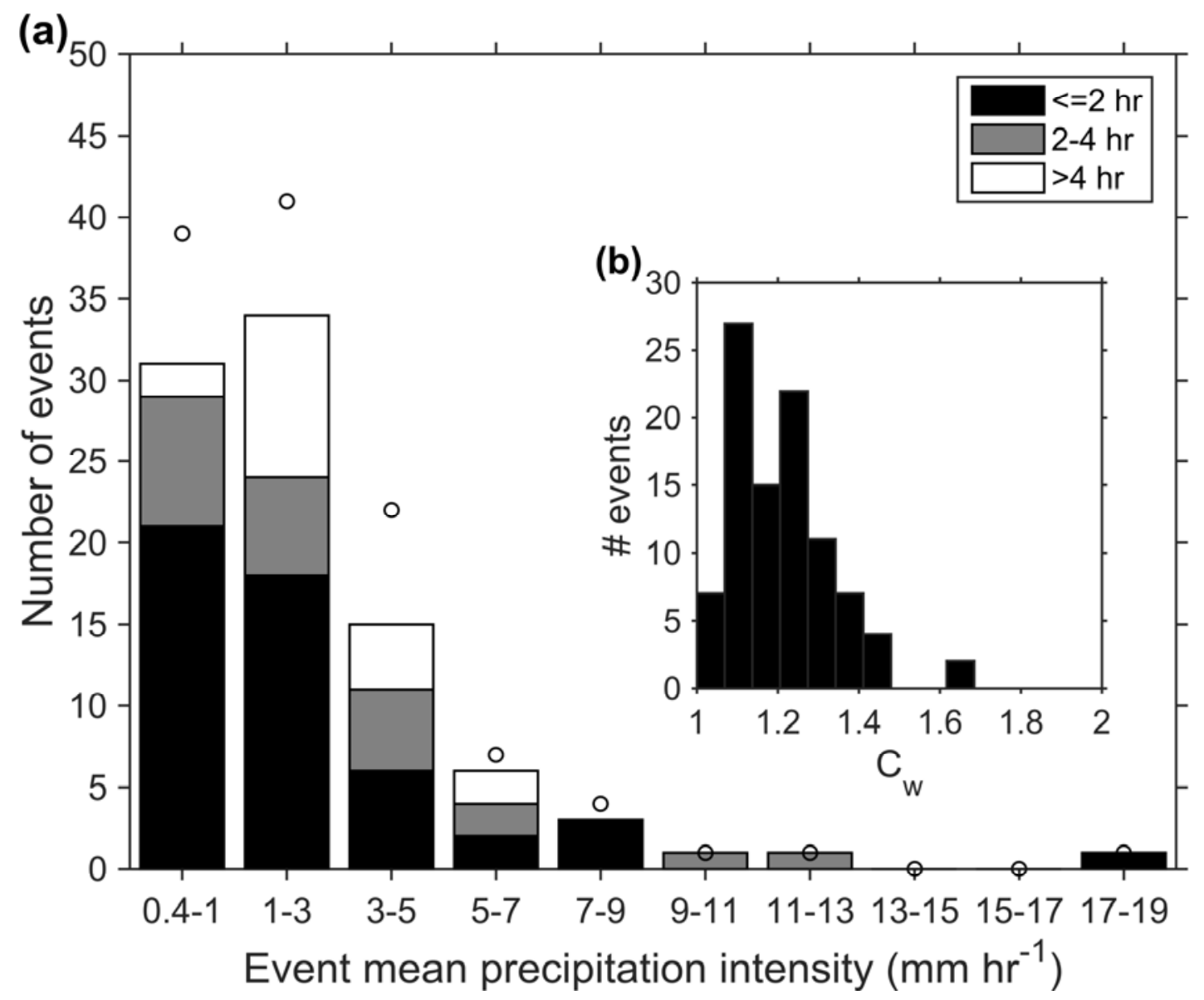

359 Figure 2 (a) Summary of the intensity (in $\mathrm{mm} \mathrm{hr}^{-1}$ ) and duration of the 95 rain events from which

360 scavenging coefficients are computed for the SMPS3936 with the long-DMA (shown by the bars).

361 Also shown are the intensities of the rainfall events (dots) included in the analysis of data from

362 the SMPS with a nano-DMA $(n=121)$. (b) Histogram of the correction factor $\left(C_{w}\right)$ for wind-

363 related under-catch by the rain gauge computed from $C_{w}=\exp [-0.001 \times \ln (R)-0.0122 \times$

$364 U \times \ln (R)+0.034 \times U+0.0077]$, where $U$ is the wind speed $\left(\mathrm{m} \mathrm{s}^{-1}\right)$, and $R$ is the measured rainfall rate $\left(\mathrm{mm} \mathrm{hr}^{-1}\right)$ (Hildebrandt et al. 2007). 

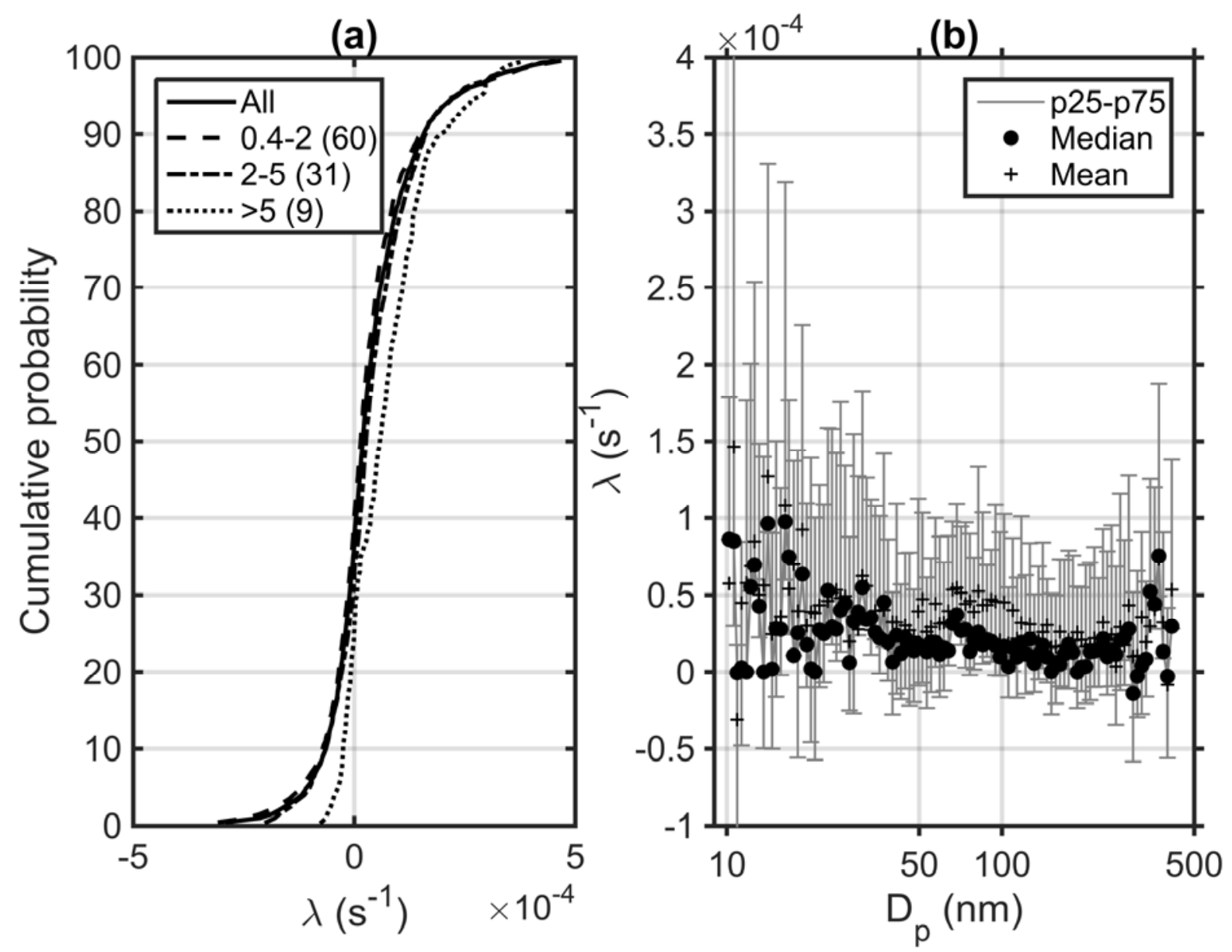

367 Figure 3 (a) Empirical cumulative distribution plot of scavenging coefficients ( $\lambda$ ) for each of the 368104 diameters $\left(D_{p}\right)$ reported by the SMPS3936 with the long-DMA for the ensemble of 95 rain 369 events at MMSF (denoted by All in the legend). Also shown are cumulative distributions of $\lambda$ 370 values conditionally sampled by three rain intensity classes (in $\mathrm{mm} \mathrm{hr}^{-1}$ ). The numbers shown in

371 parentheses are the fraction of the total number of valid $\lambda$ values in that rainfall intensity class.

372 Thus, results from the highest rainfall intensity class are the least robust since they derive from a

373 small sample size. (b) Mean, median and inter-quartile range of scavenging coefficients ( $\lambda$ ) for each of the 104 diameters $\left(D_{p}\right)$ reported by the SMPS fitted with the long-DMA. 


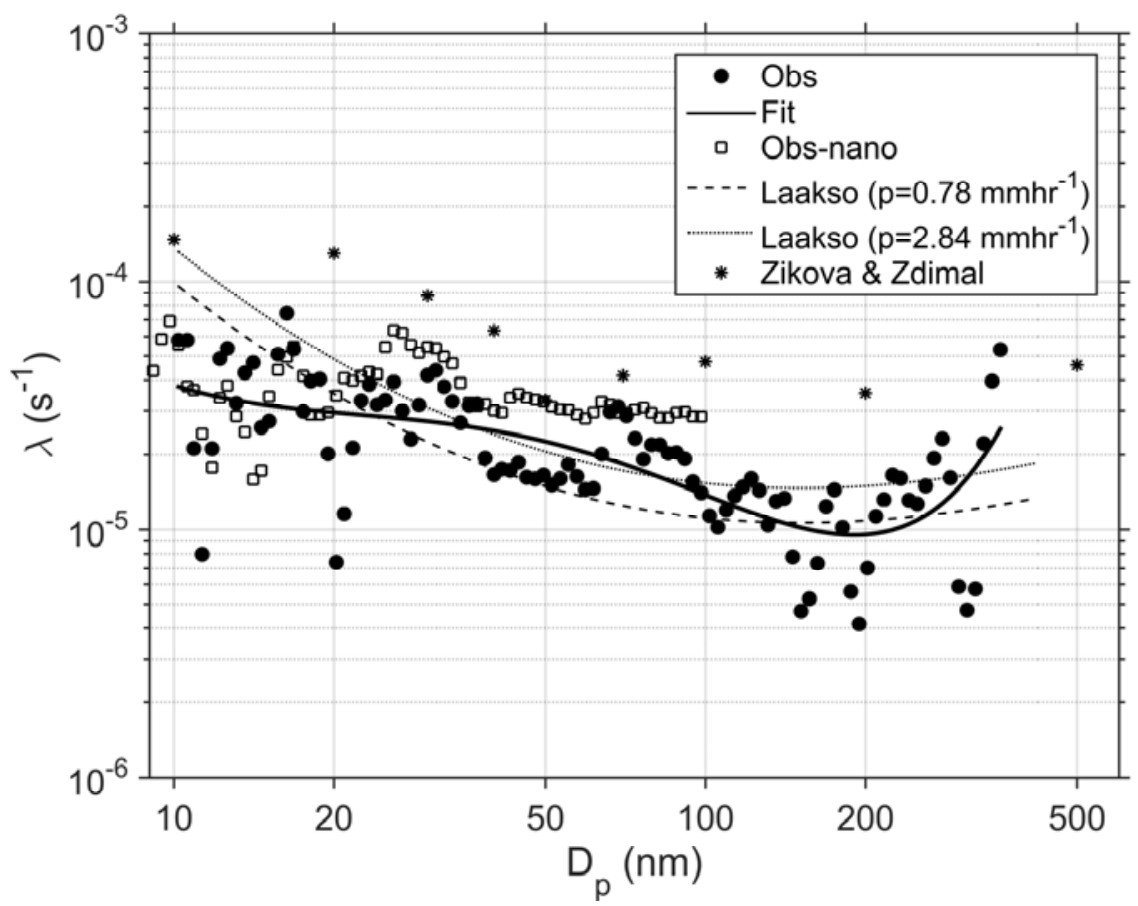

376 Figure 4 Median scavenging coefficients $(\lambda)$ as a function of particle diameter $\left(D_{p}\right)$ at MMSF as

377 used in the fitting procedure (i.e. averaged over three adjacent size classes) (Obs). Also shown is

378 a fit from equation (2) (the adjusted variance explanation $\left(r^{2}\right)$ for this fit is 0.46 ), and the median

379 scavenging coefficients as computed from the SMPS with the nano-DMA (Obs-nano). The lines

380 denote results of the parameterization of (Laakso et al. 2003) for two different precipitation rates

$381 \quad\left(p=0.78 \mathrm{~mm} \mathrm{hr}^{-1}\right.$ and $\left.2.84 \mathrm{~mm} \mathrm{hr}^{-1}\right)$. The asterisks show median scavenging coefficients as

382 presented for 311 rain events by (Zikova and Zdimal 2016) for selected particle diameters. The

383 fitting coefficients for equation (2) from MMSF and those from (Laakso et al. 2003) (shown in

384 parentheses in the format provided in the original reference) are as follows: $a=3.4549076 \times 10^{3}$

385 (274.35758), $b=1.0040252 \times 10^{7}$ (332839.59273), $c=5.484421066 \times 10^{6}(226656.57259), d=$

$3861.12147496 \times 10^{6}(58005.91340), e=1.01768617 \times 10^{5}(96588.38582), f=0.185(0.244984)$. 


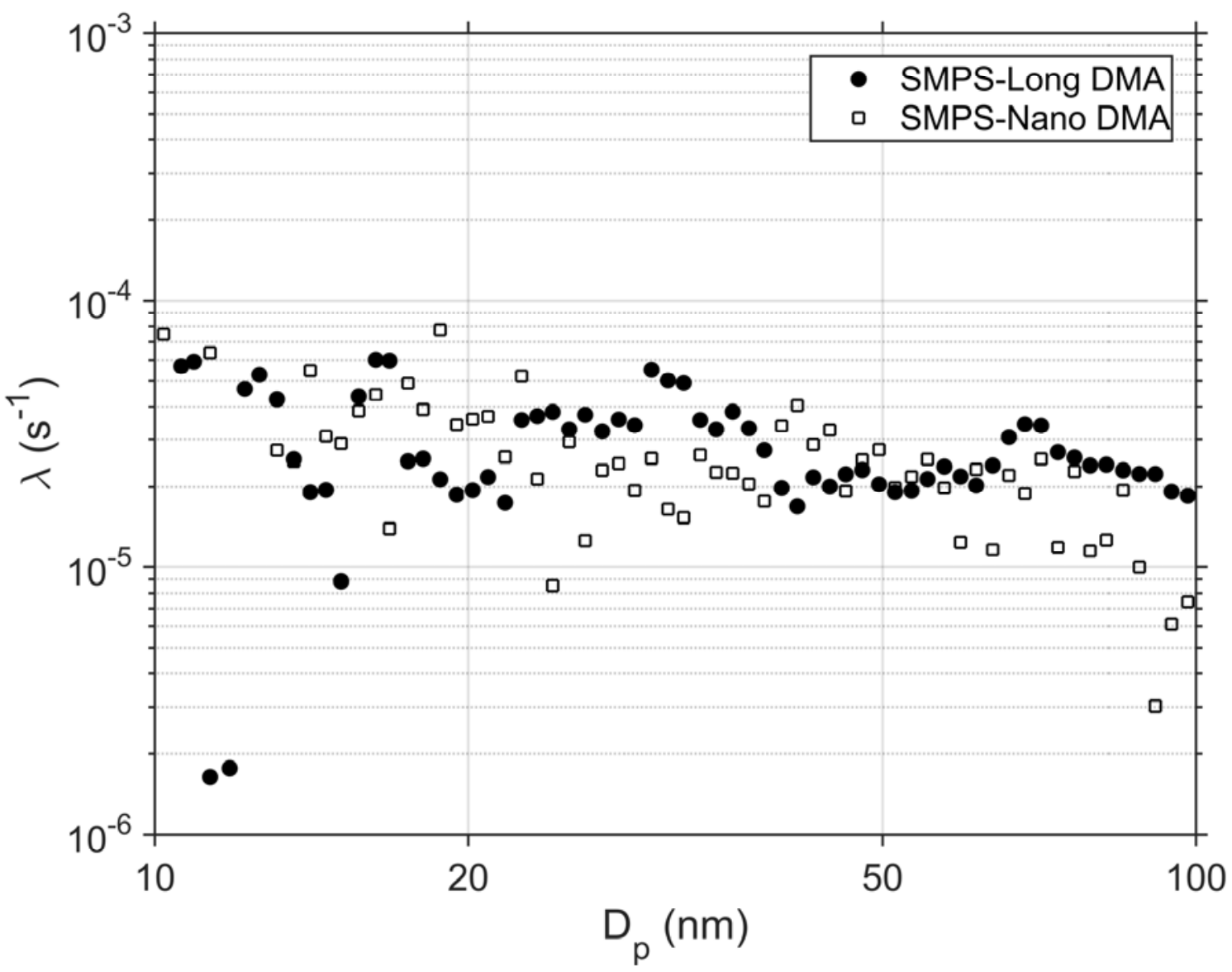

388 Figure 5 Median scavenging coefficients $(\lambda)$ as a function of particle diameter $\left(D_{p}\right)$ for diameters

389 between 10 and $100 \mathrm{~nm}$, for all 87 events for which data from the SMPS with the Long-DMA

390 (SMPS-Long DMA) and SMPS with nano-DMA (SMPS-Nano DMA) are both available. See

Table 1 for the statistics of these events.

392 